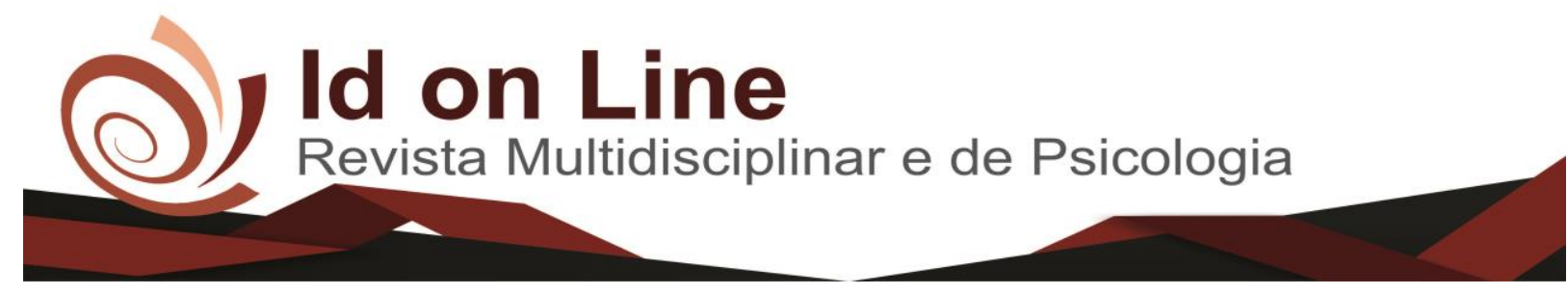

Artigo de Revisão

\title{
Sintomas Osteomusculares em Profissionais Bancários
}

\author{
Marcilene Oliveira Pinheiro ${ }^{\text {; }}$ Leonardo Costa Sampaio ${ }^{2}$
}

\begin{abstract}
Resumo: O trabalho bancário vem sofrendo profundas modificações tecnológicas e nas relações de trabalho, e essas mudanças tem causado mais desgaste físico e mental, promovendo problemas de saúde, destacando-se entre as patologias os sintomas osteomusculares que causam sofrimento e absenteísmo. Objetivos: Investigar a prevalência de sintomas de distúrbios osteomusculares em trabalhadores bancários. Especificamente, busca-se descrever o perfil sociodemográfico, apresentar variáveis funcionais e características do trabalho bancário, identificar os segmentos corporais com dor e desconforto, e analisar a frequência de queixas de dores desse profissional. Materiais e Métodos: Trata-se de uma pesquisa com abordagem quantitativa, caráter exploratório e descritivo, do tipo transversal. O estudo adotou um questionário sociodemográfico e o "Questionário Nórdico de Sintomas Osteomusculares (QNSO)”, para coletar as informações, além de realizar uma tabulação de dados, com média, desvio padrão, porcentagem e frequência. Resultados: $\mathrm{O}$ estudo diagnosticou que os bancários já tiveram desconforto osteomuscular em áreas como tornozelo e/ou pés (86,67\%), pescoço (80\%), dorsal (63,33\%) e lombar $(60 \%)$. Apontaram também frequência de dor, desconforto ou dormência, nos últimos sete dias, na região dorsal $(76,67 \%)$, lombar $(26,67 \%)$, antebraços $(16,67 \%)$ e joelhos $(3,33 \%)$. Além disso, indicaram afastamento do trabalho devido à dores em todas as regiões, destacando-se a dorsal (13,33\%), lombar $(10,00 \%)$ e pescoço $(10,00 \%)$. Conclusão: Os distúrbios osteomusculares acometem diretamente a qualidade de vida dos profissionais bancários, proporcionando o afastamento das atividades e falta de qualidade de vida. Assim, que a prevenção no ambiente laboral pode proporcionar uma grande melhora nos níveis de frequência e de produtividade.
\end{abstract}

Palavras-Chave: Bancário, Distúrbio Osteomuscular, Qualidade de Vida.

\section{Musculoskeletal Symptoms in Banking Professionals}

\begin{abstract}
Bank work has undergone profound technological changes and labor relations, and these changes have caused more physical and mental wear, promoting health problems, highlighting among the pathologies the musculoskeletal symptoms that cause suffering and absenteeism. Objectives: To investigate the prevalence of symptoms of musculoskeletal disorders in bank workers. Specifically, the aim is to describe the sociodemographic profile, to present functional variables and characteristics of the banking work, to identify the body segments with pain and discomfort, and to analyze the frequency of pain complaints of this professional. Materials and Methods: This is a research with a quantitative approach, exploratory and descriptive, of the transversal type. The study adopted a sociodemographic questionnaire and the "Nordic Osteomuscular Symptoms Questionnaire (QNSO)", to collect the information, besides tabulating data, with mean, standard deviation, percentage and frequency. Results: The study diagnosed that the workers had had musculoskeletal discomfort in areas such as ankle and / or feet $(86.67 \%)$, neck $(80 \%)$, dorsal $(63.33 \%)$ and lumbar $(60 \%)$. They also reported pain, discomfort or numbness in the last seven days, in the dorsal region $(76.67 \%)$, lumbar $(26.67 \%)$, forearms $(16.67 \%)$ and knees $(3.33 \%)$. In addition, they indicated that work was distant due to pain in all regions, especially dorsal (13.33\%), lumbar $(10.00 \%)$ and neck $(10.00 \%)$. Conclusion: Musculoskeletal disorders directly affect the quality of life of the banking professionals, resulting in the withdrawal of activities and lack of quality of life. Thus, prevention in the work environment can provide a great improvement in frequency and productivity levels.
\end{abstract}

Keywords: Professional Banking, Osteomuscular Disorders, Quality of life.

\footnotetext{
${ }^{1}$ Bacharelanda do curso de Fisioterapia da Faculdade Independente do Nordeste - FAINOR. E-mail: marcilene.pinheiro@hotmail.com ${ }^{2}$ Professor no curso de Fisioterapia na Faculdade Independente do Nordeste - FAINOR. E-mail: 1fisiosampaio@ gmail.com 


\section{Introdução}

Atualmente, o grande avanço tecnológico, principalmente nos meios de produção, tem promovido uma enorme evolução no processo de trabalho, visando maior produtividade no ambiente laboral. Essa situação, como salientam Silveira e Dias (2014), acaba por obrigar o individuo, em determinadas funções profissionais, a realizar intensos e inadequados movimentos em regiões como coluna, membros superiores, região escapular e pescoço, levando essas pessoas a frequentes desordens nessas regiões corporais.

Segundo estudo de Oliveira e Dias, (2014), o trabalho bancário tem sofrido profundas modificações, principalmente de cunho tecnológico e nas relações de trabalho, causados especialmente pela automação e crescente utilização de microcomputadores em setores produtivos. Essas mudanças acabaram promovendo novas exigências físicas e mentais aos bancários, causando mais desgaste e alterando as condições de saúde da categoria.

Sobre essas questões Burin et al. (2011) aponta que as atividades repetitivas e posturas inadequadas, estão entre os principais responsáveis pela presença de sintomas osteomusculares, em um grande número de profissionais bancários. Scopel (2010) ressalta ainda que a dor osteomuscular em funcionários bancários é ligada ao ambiente de trabalho e seus fatores organizacionais, sendo responsáveis pelo sofrimento e o absenteísmo laboral.

Em termos quantitativos a pesquisa de Peres (2007), apresenta dados informativos sobre a incidência de distúrbios osteomusculares em bancários, sendo que entre os anos de 2000 e 2005 no Brasil, foram afastados cerca de 25 mil profissionais em decorrência de LER/DORT. Num estudo mais atual, Oliveira e Souza (2015), ao analisarem os dados do Anuário Estatístico da Previdência Social do ano de 2011, vislumbraram que as doenças do sistema osteomusculares representam a segunda maior causa de concessão de benefícios de auxíliodoença, sendo que no trabalho bancário essa concessão está na primeira posição.

Entre as principais estruturas corporais que acabam se comprometendo pelos distúrbios osteomusculares, segundo Nascimento e Morais (2000), destacam-se os nervos, ossos, músculos, fáscias, tendões, bainha, sinovial, ligamentos, cápsula articular, túneis osteofibrosos, de forma isolada ou associada, com ou sem degeneração dos tecidos. Em consonância com essa informação, Bomgiormo e Tokars (2011), apontam que as dores em regiões cervicais, ombros, lombar, punhos/mãos/dedos, braços e quadril são comuns entre homens e mulheres dentro do ambiente laboral bancário. 
Dessa forma, aponta-se que esses essas patologias são um risco à saúde dos bancários e têm relação direta com o novo cenário tecnológico onde estão inseridas estas instituições, especialmente nestas duas últimas décadas, pois diante de pesquisas sobre os sintomas osteomusculares e as percebe-se que as mesmas são muito incidentes em bancários, e tem se tornado uma problemática grave, passando a ser uma demanda de saúde pública.

Assim, a realização desse estudo se justifica, pois se percebe que os sintomas osteomusculares influenciam diretamente na qualidade de vida dos bancários. Além disso, existe a necessidade de identificação e análise das principais causas desse fenômeno, para entendimento dessa demanda e apresentação de possíveis ações que possam minimizar o número expressivo de profissionais que apresentam essa sintomatologia.

Em termos de relevância, socialmente esse estudo está relacionado com a questão da qualidade de vida do bancário, pois seu ritmo de trabalho desorganizado e sem os devidos cuidados, pode promover agravos de saúde. A relevância acadêmica está relacionada ao crescimento da demanda de dor osteomuscular que influencia a saúde desse profissional.

Frente a essa realidade, esse artigo objetiva investigar a prevalência de sintomas de distúrbios osteomusculares em trabalhadores bancários. Especificamente, busca-se nesse estudo, descrever o perfil sociodemográfico dos profissionais bancários, apresentar as variáveis funcionais e as características do trabalho bancário, identificar os segmentos corporais com dor e desconforto, relacionados aos distúrbios osteomusculares, e analisar a frequência de queixas de dores com a função exercida pelo profissional dentro do banco.

\section{Metodologia}

Trata-se de uma pesquisa com abordagem quantitativa, de caráter exploratório e descritivo, do tipo transversal.

Este é um estudo frente a trabalhadores bancários na cidade de Itapetinga - Bahia. O período em que será realizada a pesquisa compreende o terceiro trimestre de 2017.

Os participantes do estudo são profissionais bancários em situação ativa de trabalho. Como critérios de Inclusão, tem-se: todos os participantes devem ser funcionários do banco e desenvolver atividades laborais cotidianas. Os critérios de exclusão foram: recusa do informante em participar da pesquisa, tempo de trabalho inferior a 3 meses. 
A partir de levantamento prévio feito na instituição bancária, a amostra compreendeu 30 sujeitos. A abordagem inicial ocorreu por meio de convite aos sujeitos, onde, a pesquisadora fez todos os esclarecimentos acerca da pesquisa, seus objetivos, riscos e benefícios e, depois de sanadas quaisquer dúvidas dos sujeitos, os mesmos assinaram o Termo de Consentimento Livre e Esclarecido (TCLE), consentindo em participar da pesquisa.

\section{Instrumentos de coleta de dados}

O estudo adotou como instrumentos de coleta de informações um questionário sociodemográfico e o "Questionário Nórdico de Sintomas Osteomusculares (QNSO)", que analisa em três áreas, uma geral (compreendendo todas as áreas anatômicas) e outras duas específicas para as regiões lombares e de pescoço e ombros.

\section{Procedimentos}

Primeiramente foi apresentado o projeto a gerente da agência bancária, onde foi autorizada a realização da pesquisa. Em seguida o projeto foi submetido ao Comitê de ética de acordo as exigências da resolução 466/12 para pesquisas com seres humanos. Logo após foi feito o contato com a gerência da instituição bancarias onde ocorreu uma análise com sua equipe determinando o dia da coleta de dados. Após esses procedimentos preliminares, foi realizado um contato pessoal com os participantes, onde se explicou a finalidade e o objetivo da pesquisa. Após consentimento em participar da pesquisa foi entregue o Termo de Consentimento Livre e Esclarecido (TCLE) (APÊNDICE A) e somente após a assinatura do termo, a pesquisa se iniciou. Após assinar o Termo de Consentimento Livre e Esclarecido (TCLE), o participante primeiramente respondeu um questionário estruturado para obter os dados que foram analisados e discutidos no trabalho de pesquisa (APÊNDICE B). A aplicação do questionário foi realizada em uma das salas disponíveis na instituição bancária.

A análise dos dados do estudo realizou-se de forma descritiva, utilizando a tabulação de dados, com média, desvio padrão, porcentagem e frequência através do programa Excel 2013 que em seguida foram submetidos ao software SPSS 23.0. Para tanto, um cálculo amostral foi 
realizado baseando-se no erro amostral de 5\% e no nível de confiança de 90\%, dentre os entrevistados.

Com relação às questões éticas, os participantes da pesquisa foram devidamente esclarecidos quanto aos objetivos do trabalho, ficando livres para participar ou não. Uma vez aceitando, assinaram o Termo de Consentimento Livre e Esclarecido TCLE (APÊNDICE A), sendo respeitados os princípios éticos que constam na resolução 466/12 do Conselho Nacional de Saúde. A desistência ou não participação não implicou em prejuízo ao indivíduo na instituição. O estudo foi submetido ao CAAE parecer 72591717.7.0000.5578, Comitê de Ética em pesquisa da Faculdade Independente do Nordeste (CEP/FAINOR) para autorização da pesquisa e aplicação do questionário.

\section{Resultados e Disussão}

Foram entrevistados 30 trabalhadores, todos em pleno exercício profissional, provenientes de uma instituição bancária pública situada na cidade de Itapetinga Bahia.

Nesse estudo, na análise de dados socioeconômicos dispostos na Tabela 1, verificou-se que a maior parte da amostra é composta por homens (60,00\%), com idade entre 31 e 40 anos (46,67\%), apresentando uma escolaridade média de Ensino Superior Completo (33,33\%). Aponta-se ainda que a maioria dos profissionais participantes do estudo possuem companheiro/marido (63,33\%), tem uma jornada média de trabalho entre 6 e 7 horas diárias $(56,67 \%)$, e realizam a prática de atividade física $(66,67 \%)$ em pelo menos 3 horas semanais.

Tabela 1. Características das variáveis socioeconômicas do estudo. Itapetinga-Bahia, Brasil.2017

\begin{tabular}{lll}
\hline Variáveis & $\mathrm{N}$ & $\%$ \\
\hline Sexo & & \\
$\quad$ Masculino & 18 & 60,00 \\
Feminino & 12 & 40,00 \\
& & \\
Grupo Etário & & \\
$\quad$ entre 18-20 anos & 00 & 00,00 \\
entre 21-30 anos & 06 & 20,00 \\
entre 31-40 anos & 14 & 46,67
\end{tabular}




\section{Escolaridade}

Médio Incompleto $\quad 00$

00,00

Médio Completo

02

06,67

Superior Incompleto

07

23,33

Superior Completo

10

33,33

Especialização Incompleta

05

16,67

Especialização Completa

06

20,00

\section{Estado Civil}

Sem Marido (Esposa) /Companheiro (a)

Com Marido (Esposa) /Companheiro (a)

\section{Jornada Média de Trabalho}

6 horas

Entre 7 e 8 horas

Acima de 8 horas

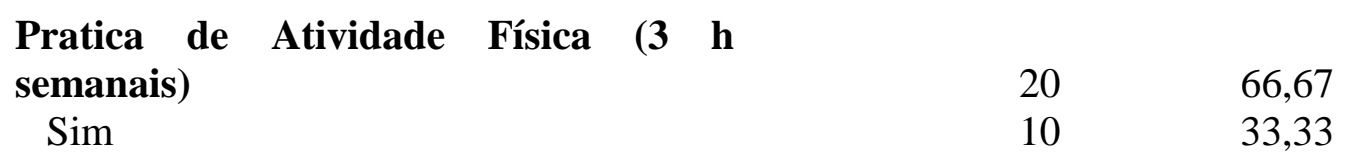

Não

\section{TOTAL}

Em relação aos dados socioeconômicos verificados nesse estudo notam-se com relação ao sexo e idade verificados, nota-se semelhança em Bomgiorno e Tokars (2011), que em sua pesquisa frente a 57 bancários na cidade de Curitiba- PR, diagnosticaram que a maior parte eram homens $(65 \%)$ com idade média próxima aos 30 anos (29,4 anos). Outra pesquisa que assinala resultado semelhante ao desse estudo é o de Silveira e Dias (2014), que numa amostra de 17 trabalhadores bancários, evidenciou-se que a maioria era do sexo feminino (53\%), com idade média de 35 anos. No entanto, esses resultados da frequência relativa dos participantes da pesquisa segundo sexo, tem resultados divergentes em outras pesquisas, como a de Burin et al (2011) que aponta uma quantidade maior de bancários do sexo feminino $(50,8 \%)$ entre os entrevistados.

Quanto à escolaridade, estado civil, jornada de trabalho, nota-se semelhança de resultados em diversos estudos, como o de Scopel (2010), onde o mesmo diagnosticou, numa amostra de 355 bancários, que a maioria dos bancários possuía nível superior (71,3\%), 
possuíam companheiro $(57,9 \%)$ e trabalhavam de 6 á 8 horas diárias $(60,6 \%)$. Zavarizzi e Alencar (2014), também apontam em seus estudos resultados semelhantes aos detectados nesse estudo, pois em sua amostra de bancários pesquisada, aponta-se que a maior parte possuiu ensino superior completo (60\%), e trabalham mais de seis horas diárias $(80 \%)$. Outro estudo mais atual e que apresenta resultado similar ao encontrado nesse trabalho é o de Nunes e Mascarenhas (2016), que verificou frente aos bancários entrevistados que os mesmos referiram possuir ensino superior completo $(53,2 \%)$, ter uma carga horária semanal maior que 30 horas $(58,6 \%)$, e em sua grande maioria $(70,3 \%)$ possuíam união estável.

Em relação a pratica de atividades físicas regulares, Burin et al (2011) verificou em seu estudo que a maior parte dos participantes da pesquisa $(69,57)$ realizam atividades físicas de forma regular, estando esse resultado em consonância com o encontrado nesse trabalho. Nunes e Mascarenhas (2016) também buscaram essas informações frente à amostra de 111 bancários por eles entrevista, e notou que a maior parte dos pesquisados indicaram ter um bom estilo de vida (69\%), sendo que uma das atividades realizadas fora do ambiente laboral é a prática de atividades físicas.

As informações contidas na Tabela 2 referem-se frequência de dor, desconforto ou dormência, nos últimos 12 meses, apresentadas pelos bancários. Nota-se que a maioria da amostra aponta que já tiveram desconforto osteomuscular em áreas como tornozelo e/ou pés $(86,67 \%)$, no pescoço $(80 \%)$, na região dorsal $(63,33 \%)$ e lombar $(60 \%)$. Outras regiões também foram apontadas, mais com menor frequência, tais como ombros (40\%), quadris e/ou coxas $(33,33 \%)$, antebraços $(16,67 \%)$, punhos/mãos/dedos $(13,33 \%)$, cotovelos $(6,67 \%)$ e joelhos $(3,33 \%)$.

Tabela 2. Frequência de dor, desconforto ou dormência, nos últimos 12 meses. ItapetingaBahia, Brasil, 2017.

\begin{tabular}{lcc}
\hline Variáveis & $\mathrm{N}$ & $\%$ \\
\hline Pescoço & & \\
Sim & 24 & 80,00 \\
Não & 06 & 20,00 \\
& & \\
Ombros & & 40,00 \\
Sim & 12 & 60,00 \\
Não & 18 &
\end{tabular}

\section{Cotovelo}


Sim

\section{Antebraço}

Sim

Não

\section{Punhos/Mãos/Dedos}

Sim

Não

\section{Região Dorsal}

Sim

Não

\section{Região Lombar}

Sim

Não

\section{Quadris e/ou coxas}

Sim

Não

\section{Joelhos}

Sim

Não

\section{Tornozelos e/ou pés}

Sim

Esses dados aqui verificados, com maior frequência de dor nos tornozelos e/ou pés, no pescoço, na região dorsal e lombar, encontram em Silveira e Dias (2014) alguma semelhança visto que a dor lombar (100\% mulheres e 50\% homens), dorsal (75\% mulheres e $67 \%$ homens), pescoço (63\% mulheres e 67\% homens), e nos membros inferiores (50\% mulheres e 50\% homens), são indicados por mais da metade dos pesquisados como dores prevalecentes nos últimos doze meses.

No entanto, outros trabalhos indicam resultados diversos em relação à área acometida, como os dados de Burin et al (2011) em que destaca-se que a maior parte dos pesquisados 
$(67,39 \%)$ apresentaram algum acometimento do ombro, seguido de relatos na coluna cervical (53\%), no punho $(45,65 \%)$, na mão $(36,96 \%)$, no cotovelo $(32,61 \%)$, e na coluna lombar $(21,72 \%)$.

No estudo, de Nunes e Mascarenhas (2016), com abordagem bem próxima a deste trabalho, verificou-se que as regiões mais acometidas nos últimos 12 meses foram: pescoço $(49,5 \%)$, lombar e ombro $(45,6 \%)$ e punho/mão/dedos $(35,1 \%)$, mostrando semelhança de acometimento em áreas como o pescoço e a lombar, muito citado nesta pesquisa.

As informações contidas na Tabela 3 referem-se frequência de dor, desconforto ou dormência, nos últimos 07 dias. Os resultados indicam que a maioria da amostra $(76,67 \%)$ indica dor na região dorsal, seguido da lombar (26,67\%), antebraços $(16,67 \%)$ e joelhos $(3,33 \%)$. O restante das regiões não foi citado pelos bancários pesquisados

Tabela 3. Frequência de dor, desconforto ou dormência, nos últimos 07 dias. Itapetinga-Bahia, Brasil, 2017.

\begin{tabular}{|c|c|c|}
\hline Variáveis & $\mathrm{N}$ & $\%$ \\
\hline \multicolumn{3}{|l|}{ Pescoço } \\
\hline Sim & 06 & 20,00 \\
\hline Não & 24 & 80,00 \\
\hline \multicolumn{3}{|l|}{ Ombros } \\
\hline Sim & 00 & 00,00 \\
\hline Não & 30 & 100,0 \\
\hline \multicolumn{3}{|l|}{ Cotovelo } \\
\hline Sim & 00 & 00,00 \\
\hline Não & 30 & 100,0 \\
\hline \multicolumn{3}{|l|}{ Antebraço } \\
\hline Sim & 05 & 16,67 \\
\hline Não & 25 & 83,33 \\
\hline \multicolumn{3}{|c|}{ Punhos/Mãos/Dedos } \\
\hline Sim & 00 & 00,00 \\
\hline Não & 30 & 100,0 \\
\hline \multicolumn{3}{|c|}{ Região Dorsal } \\
\hline Sim & 23 & 76,67 \\
\hline Não & 07 & 23,33 \\
\hline
\end{tabular}




\section{Quadris e/ou coxas}

Sim

Não

\section{Joelhos}

Sim

Não

\section{Tornozelos e/ou pés}

Sim

Não

Mediante os dados apresentados observa-se que somente quatro regiões são citadas pelos bancários como causadoras de dor, desconforto ou dormência, nos 07 dias anteriores a pesquisa, sendo elas a região dorsal, a lombar, os antebraços e joelhos.

No entanto, devido à complexidade dessa abordagem, visto que somente pouquíssimos trabalhos realizaram estudos para analisar uma frequência desse tipo. Entre esses trabalhos, a pesquisa de Nunes e Mascarenhas (2016) é uma das que pode ser usada para comparação com os resultados encontrados neste estudo. Segundo esses autores, a maior sintomatologia de dor osteomusculares em bancários verificada nos últimos sete dias anteriores à pesquisa, apontam que a região lombar $(34,2 \%)$, pescoço e ombro $(32,4 \%)$, e punho/mão/dedos $(25,2 \%)$, porém a região dorsal $(21,6 \%)$, dos antebraços $(16,2 \%)$ e dos joelhos $(15,3 \%)$ também é citada, o que mostra semelhança dos resultados observados com este estudo.

Sobre essa questão, mas em trabalhos relacionados a outras categorias profissionais nota-se que a sintomatologia osteomuscular varia, visto que o tipo de trabalho também é alterado. Assim, na pesquisa de Souza e Neto (2015), em que se analisou a sintomatologia osteomuscular em funcionários administrativos de um órgão público observou-se que nos últimos sete dias, as regiões mais sinalizadas com dor foi a lombar (61\%), seguida pelo punho/mão/dedo (59\%), e pelo pescoço (53\%), mostrando correlação de frequência de dor na região lombar com este estudo. 
Outra abordagem desta pesquisa estudo é apresentada na Tabela 4 e se refere à necessidade de evitar ou suspender suas atividades devido a problemas nessas regiões nos últimos 12 meses. Os dados coletados mostram que os bancários já foram obrigados a se afastar do trabalho devido à dor em todas as regiões, mas numa frequência muito pequena, sendo que a dorsal $(13,33 \%)$, lombar $(10,00 \%)$ e pescoço $(10,00 \%)$, foram as mais assinaladas pela amostra.

Tabela 4. Necessidade de evitar ou suspender suas atividades devido a problemas nessas regiões nos últimos 12 meses. Itapetinga-Bahia, Brasil, 2017.

\begin{tabular}{lcc} 
Variáveis & $\mathrm{N}$ & $\%$ \\
\hline Pescoço & & \\
Sim & 03 & 10,00 \\
Não & 27 & 90,00
\end{tabular}

\section{Ombros}

Sim

02

06,67

Não

\section{Cotovelo}

Sim

Não

\section{Antebraço}

Sim

Não

\section{Punhos/Mãos/Dedos}

Sim

Não

\section{Região Dorsal}

Sim

Não

\section{Região Lombar}

Sim

Não

\section{Quadris e/ou coxas}

Sim

Não 
Sim

\section{Tornozelos e/ou pés}

Sim

Em consonância com esses resultados, Souza e Neto (2015), apontam que as regiões mais sinalizadas com dor pelos trabalhadores participantes da pesquisa, e que impediu os mesmos de trabalhar, foi a lombar (27\%), dorsal (20\%), pescoço (18\%) e joelho (18\%), mostrando grande correlação com os dados desse estudo.

Nunes e Mascarenhas (2016) diagnosticaram que a maior sintomatologia de dor osteomusculares em bancários causadores de afastamentos foi o ombro $(16,2 \%)$, a lombar $(12,6 \%)$, e punho/mão/dedos $(11,7 \%)$, mostrando também resultados similares visto que a lombar aparece entre as principais em ambos os trabalhos.

Bomgiorno e Tokars (2011), também relatam em seu trabalho o afastamento de bancários devido à existência de dores osteomusculares e enumera as regiões cervical, dorsal e ombros, como as que mais causaram afastamento dos bancários. Em relação a este estudo, notase semelhança de resultados na dor dorsal que aparece entre as mais citadas.

Destaca-se assim, que a prevenção de distúrbios osteomusculares no ambiente de trabalho bancário pode proporcionar ao profissional e para a empresa uma grande melhora nos níveis de frequência e consequentemente de produtividade.

\section{Conclusão}

Mediante os resultados obtidos com esse estudo, percebeu-se uma grande frequência de sintomas de dores osteomusculares relatadas pelos bancários participantes da pesquisa. Nesses dados notabilizou-se que tanto nos últimos 12 meses, como nos últimos 7 dias anteriores à pesquisa, bem como em relação aos motivos de afastamento nos últimos 12 meses, estiveram entre as regiões mais acometidas foram o pescoço, a região dorsal e a região lombar. 
Assim, a partir da verificação da associação dessas variáveis, pode-se enumerar que as mesmas acometem diretamente a qualidade de vida dos profissionais bancários, pois podem proporcionar o afastamento das atividades e a falta de qualidade de vida.

Portanto, os dados colhidos neste estudo e a análise efetiva dos mesmos é um passo essencial para que os bancários e as empresas possam nortear as atividades profissionais, através da adoção de atitudes e estratégias para promoção da saúde e que favoreçam a melhoria qualidade de vida.

Por fim, considera-se aqui a importância da realização de outros estudos que investiguem as demandas que envolvem a prevalência de dores osteomusculares entre os trabalhadores de instituições bancárias, com o intuito de verificar as razões das mesmas, bem como favorecer o desenvolvimento de ações voltadas ao impedimento do surgimento dessas patologias nesse ambiente laboral.

\section{Referências}

BOMGIORNO, A.; TOKARS, E. Prevalência dos Sintomas de Distúrbios Osteomusculares em Bancários da Cidade De Curitiba. Universidade Tuiuti do Paraná, 2011. Disponível em http://tcconline.utp.br/wp-content/uploads/2011/04/PREVALENCIADO S-SINTOMAS-DEDISTURBIOS-OSTEOMUSCULARES-EM-BANCARIOS-DA-CIDAD DECURITIBA.pdf. Acesso em: 20/03/2017.

BRANDÃO, A. G. et al. Sintomas de distúrbios osteomusculares em bancários de Pelotas e região: prevalência e fatores associados. Revista Brasileira de Epidemiologia, Vol. 8(3), 2005.

BURIN, T. et al. Presença de LER/DORTS em um grupo de bancários da cidade de ErechimRS. Revista Perspectiva, Erechim. v.35, n.129, Março, 2011.

NASCIMENTO, N. M.; MORAES, R. A. S. Fisioterapia nas empresas: saúde x trabalho. $2^{\text {a }}$ ed. Rio de janeiro: Taba Cultural, 2000.

NUNES, E. A.; MASCARENHAS, C. H. M. Qualidade de vida e fatores associados em trabalhadores do setor bancário. Revista Brasileira de Medicina do Trabalho, 14 (3), 2016.

OLIVEIRA, R. A.; SOUZA, S. T. M. Lesões por Esforços Repetitivos / Distúrbios Osteomusculares relacionados à atividade Bancária. Revista Eletrônica Sistemas \& Gestão, Volume 10, Número 1, 2015. 
PERES, L.. País gasta R \$ 981 milhões com LER em bancários. Artigo publicado em 29 de abril de 2007. Jornal Folha de São Paulo. Disponível em: http://www1.folha.uol.com.br/ folha/dinheiro/ult91u116625.shtml. Acesso em: 22/03/2017.

SCOPEL, J. Dor Osteomuscular em Membros Superiores e Casos Sugestivos de LER/DORT entre Trabalhadores Bancários. Dissertação (Mestrado) - Universidade Federal do Rio Grande do Sul. Faculdade de Medicina. Programa de Pós-Graduação em Epidemiologia. Porto Alegre, BR-RS, 2010. Disponível em: http://www.lume.ufrgs.br/handle /10183/24322 Acesso em 20 de Março de 2017.

SILVEIRA, A. O. A; DIAS, E. G. Sintomas e Distúrbios Osteomusculares em Bancários da Cidade de Porteirinha-MG. Revista de Biologia e Farmácia - BioFar, ISSN 1983-4209 Volume 10 - Número 01 - 2014.

SOUZA, K. V. L.; NETO, M. G. Análise da Qualidade de Vida e Distúrbios Osteomusculares dos Funcionários Administrativos de um Órgão Público. Revista Pesquisa em Fisioterapia, Dez; Vol. 5(3), 2015.

ZAVARIZZI, C.; ALENCAR, M. C. B. Aspectos relacionados ao afastamento de bancários por LER/DORT. Caderno Terapia Ocupacional, UFSCar, São Carlos, v. 22, n. 3, 2014.

Como citar este artigo (Formato ABNT):

PINHEIRO, Marcilene O.; SAMPAIO, Leonardo C. Sintomas Osteomusculares em Profissionais Bancários. Id on Line Revista Multidisciplinar e de Psicologia, 2017, vol.11, n.38, p. 223-236. ISSN: 1981-1179.

Recebido: 22.10 .2017

Aceito: 25.10.2017 